\title{
Exploring Policy-Formulation for SMEs in Cloud Computing: The Case of Turkey
}

\author{
Asli Deniz Helvacioglu Kuyucu \\ Department of International Trade, Bogazici University, Istanbul, Turkey
}

\begin{abstract}
The promise of competitiveness that clouds offer to enterprises creates a substantial part of the cloud phenomenon. 2010 European Union report on cloud computing identifies the strong commercial nature of clouds and addresses new policies and actions for the competitiveness of European industry. Today, European Union attributes competitiveness to the smart growth of SMEs. The concept of smart growth is based on effective policies that foster innovation and capability to adopt the dynamics of information society. This paper aims at exploring the policymaking methods for cloud computing that will serve to enhance the competitiveness of SMEs. It analyses the dynamics of Turkish policy-making and discusses the role of EU policies in a candidate country as the motivators of migration to clouds. It is an output of an ongoing research on cloud computing in Turkey. This paper contributes to the literature as being one of the first studies on policy-making for cloud computing. It provides a twofold policy tool proposed for policy-makers. First, it identifies the dynamics of policy-making by adapting the model of Van Schendelen's general categories of decision buttons for EU lobbying to the Turkish policy-making mechanisms. Secondly, it detects the main patterns of cloud computing policy under five priority areas as a check list for policy-makers.
\end{abstract}

Keywords: Cloud Computing, European Union, Policy-Making, Turkey

\section{Introduction}

Cloud computing has turned out to be one of the hottest topics. It offers a wide area of research, most of which is still unexplored. This is also reflected to the variety of definitions (Vaquero et al., 2009). There are many different definitions for clouds. National Institute of Standards and Technology, Information Technology Laboratory (NIST, 2010) defines cloud computing as "a model for enabling convenient, on-demand network access to a shared pool of configurable computing resources (e.g., networks, servers, storage, applications, and services) that can be rapidly provisioned and released with minimal management effort or service provider interaction." European Community for Software and Software Services (ECSS, 2010) describes cloud computing as "the delivery of computational resources from a location other than your current one". Accordingly, it is a style of computing in which IT-related capabilities are provided "as a service" allowing users to access technology-enabled services from the Internet without knowledge of, expertise with, or control over the technology infrastructure that supports them. The

Copyright (C) 2011 Asli Deniz Helvacioglu Kuyucu. This is an open access article distributed under the Creative Commons Attribution License unported 3.0, which permits unrestricted use, distribution, and reproduction in any medium, provided that original work is properly cited. Contact Author: Asli Deniz Helvacioglu Kuyucu Email: asli.helvacioglu@boun.edu.tr 
definition that the European Union (EU) publications refer to, bears a broader perspective and explains the cloud as an elastic execution environment of resources involving multiple stakeholders and providing a metered service at multiple granularities for a specified level of quality (of service) (Jeffery and Neidecker-Lutz, 2010).

All definitions, in the end, highlight that clouds are dynamic, flexible, customizable and cost-based efficient. These aspects make the cloud phenomenon grow more and more each day. IDC predicts that in 2013, worldwide cloud services will reach to $\$ 44.2$ bn with a European market of $€ 6,005 \mathrm{~m}$ (Gorniak, 2009). This signifies that migration to cloud computing becomes a strategic choice of competitive advantage for companies. IDC's 2009 report "Cloud-based application development and test services: customers leading requirements and provider preferences" held among 400 IT and line of business executives in the US and Europe, concludes that larger enterprises are going down the cloud route in drives, in search of greater cost efficiencies and faster times to market for application development and testing services (Stinchcombe, 2009). The results from 2010 CIO survey on business priorities and strategies (Gartner Executive Programs, 2010) show that CIOs rank cloud computing second among top ten technology priorities, addressing it as a collaborative and productive solution to accelerate information technology (IT) transition from a support function to strategic contributor focused on innovation and competitive advantage. Accordingly, $71 \%$ of companies believe that cloud computing is a real technology option whereas, $70 \%$ hold that it would make their business flexible and $62 \%$ think that it would help them react quickly to market conditions (Misra and Mondal, 2010).

As big corporate companies hype the clouds, there is also a tendency among small and medium-sized enterprises (SMEs). Etro (2009) claims that diffusion of cloud computing could provide a positive and substantial contribution to the annual growth rate (up to a few decimal points), helping to create about a million new jobs through the development of a few hundred thousand new SMEs in the European Union (EU). SMEs believe that clouds enable fast access to best business applications or drastically boost infrastructure resources, all at negligible cost (Subashini and Kavitha, 2010). Cloud computing technologies enable SMEs to develop cost effective business models where they only have to pay only for the operating cost as capital investment, security, backup and server maintenance costs rest all among the provider's responsibilities (Sharma et al., 2010). Studies focusing on SME perspectives for cloud computing highlight that SMEs show positive attitudes towards the market need for cloud computing (Redmond et al., 2010)

The assumptions for the boost of cloud computing are clearly thrilling at these times when the world economy is facing some real challenges and there is a certain need for an economic recovery. Sultan (2010) claims that cloud computing is likely to be proved commercially viable for many small and medium enterprises (SMEs) due to its flexibility and pay-as-you-go cost structure, particularly in the current climate of economic difficulties. Cloud providers appreciate the system as it is a functional solution to SMEs' high-cost technology investments. Clouds enable reduction of cost and effort through outsourcing and automation of essential resource management (Jeffery and Neidecker-Lutz, 2010). In this regard, policies that stimulate SME competitiveness would have an important role in structuring cloud computing within the economy. Cloud computing policies shall therefore, be an important complement for SMEs not only, to enhance competitiveness in this new, revolutionary era but also to attain sustainable, efficient economic development. Migration to cloud can be a source for competitiveness if the SMEs are ready to adopt a cloud-oriented way of organizing and 
accessing the technological infrastructure. So the policies that are designed for clouds should work for stimulating a migration path which is based on agility and innovation.

The most challenging part of SME policies lies in the fact that the major expectancy of SMEs from policy-makers is to achieve better access to finance. The competitiveness of SMEs is very much related with their flexible structure that helps them to be more rapid taking the essential management decisions as well as being able to modify their production in accordance with the changes in the market. At the very same time, SMEs face financial constraints and they depend upon the sustainability of the revenues. Therefore cost of anything is important for SMEs. Parallel to this need, clouds are marketed with their cost-saving feature which is quite revolutionary. Clouds offer a new way of business which aims at optimizing cost in positive ways. However, clouds cannot be a right track of cost-saving as long as the SMEs do not know how to use it. Plus, it may open up a new cost frame which is the broadband connection. Therefore, policy-making for clouds should be an interdisciplinary work that includes competitiveness, finance, technology and law.

This paper aims at exploring the potential of cloud computing policies for the competitiveness of SMEs by analyzing the patterns of Turkish SME policy. A special emphasis is given to the EU policies as Turkey's candidate status brings forward harmonization with EU. The paper discusses SME policies in Turkey by referring to the EU approach which provides a basis for policymaking for cloud computing as a part of Turkey's candidate status. It is one of the first outputs of an ongoing research on cloud computing in Turkey and contributes to the literature as one of the first studies on this issue.

The first part of the paper focuses on the dynamics of policy-making in EU harmonization process and identifies the major points of SME policies in Turkey and
EU, whereas the second part provides a twofold policy tool proposed for policymakers in Turkey. The paper highlights policy-formulation in Turkey by adapting the model of Van Schendelen's general categories of decision buttons for EU lobbying to the Turkish policy-making mechanisms. This modeling is a novel contribution to the literature as it uses European mechanism for domestic policy-making system for the first time. Lastly, the paper detects the main patterns of a possible cloud computing policy for Turkey under five priority areas. Those patterns are provided as a checklist for policy-makers.

\section{Policy-Learning in the Light of the EU Exposure}

Turkey's candidate status provides a basis for many policy areas that are subject to EU accession negotiations. EU harmonization process is mainly the process of adoption and adaptation of what EU offers in terms of legal, economic and policy-oriented outputs, in accordance with the dynamics of the candidate country. In some policy areas, like agriculture and environment, this process may turn into a very complex issue as there are conflicts between the national and Community interest. However, in new and emerging policy areas, the guidance of EU may lead to new opportunities for the candidate country. Best practices of the EU experience may assist the candidate country to adopt more efficient and effective policies.

The theme of information society corresponds to the themes of the era of globalization and constitutes main point of global policy efforts (Drori, 2007). The tendency to favor the search for a universal model of the information society remains very strong especially within the institutions of policy-making (Mansell, 2009). As seen in innovation policy, in new, technologyfocused policy areas, policy makers need sufficient competences and expertise for the identification of problems, in order to find appropriate solutions and instruments for the implementation of policy measures 
(Koschatzky, 2009). However, in developing countries, there is a sense of urgency in policy-making for the issues covered by the information society agenda which is a result of a perceived need to 'catch up' with the rest of the world (Duncan-Howell et al., 2008). The lack of consistency between policy design and the actions proposed to achieve the objectives of the policy may result in an unsustainable environment where the actors loose competitive advantage dramatically (Castro-Martinez et al., 2009, Duncan-Howell et al., 2008, Mollas-Gallart and Davies, 2006). EU, acting as a role model, may advance policy-learning process (Koschatzky, 2009) and also create a benchmark for the creation of favorable conditions. However, it should be mentioned that a complete copy-paste approach to policy-making which is based on adoption of best practices can only represent a standard endowment but not a guarantee for an easy win (Piccaluga, 2009). The effectiveness and efficiency of the proposed policy derives from the ability of the candidate country to use the EU practices and policy priorities as the basis to adopt differentiated national policies that are also internationally compatible. Accordingly, country specific features and policy priorities depict systems where policy responses are more effective in achieving national goals (Guinet, 2010). Information and communication technology policies are better to be comprehensive and created in line with local norms, values, and culture in order to meet the socio-economic needs and objectives like poverty reduction, and improvement of quality of life (Kendall et al., 2006).

\section{SME Policies in EU and Turkey under the Scope of Information Society}

In EU, over $99 \%$ of EU enterprises are SMEs and they provide over two thirds of private sector jobs, including $80 \%$ of new jobs created in EU over the last five years (European Commission, 2009). This can be seen as a quasi requirement for EU to adopt articulated and ambitious policies for SMEs. Europe 2020 (European Commission, 2010), recently introduced European strategy for smart, sustainable and inclusive growth, presents the dawn of a new SME policy which is mostly supported by information and communications technology (ICT) schemes. This strategy reframes the SME policy of EU to support the development of a strong and sustainable industrial base that will help EU to compete globally. It covers better conditions for business to innovate and more functional EU instruments to support innovation, especially in the field of ICTs. EU wants to reinforce Europe's technology strength in key strategic fields in order to stimulate ICT innovation across all business sectors. As stated in the Lisbon Agenda, EU continues to work for to achieve the most competitive knowledge-based economy in the world.

SME policy remains to be one of the policy areas where Turkey has aligned herself with EU. Parallel to the EU objectives, the 9th Development Plan of Turkey (2007-2013) which is prepared with the vision of being a country of information society, states that Turkey should work to achieve global competitiveness and aim at fully completing her integration with European Union. This Development Plan sets the vision for SMEs under the competitiveness title and identifies SME policies within three main objectives; access to finance, efficient support schemes and innovation and modernization as an integrated part of information society.

The basis for SME policies in Turkey is the SME Strategy and Action Plan (Planning Organization, 2004) which is prepared in the light of the European Charter for Small Enterprises. It is a document bringing the European approach to SMEs in Turkey. In 2005, Turkey adopted the new SME definition which is also totally in line with the EU approach. An updated SME Strategy and Action Plan (2007-2009) are adopted, after the publication of the 2006 Accession Partnership Document which emphasized the importance of business environment for SMEs. This new version of SME strategy set five targets; improvement of 
entrepreneurship, enterprise development, integration of SMEs into international market, improvement of business environment and the development of technological and innovative capacity of SMEs.

Today, SME policies constitute a considerable part of Turkish enterprise policy. In such a modular and multiple knowledge economy, where the global market is dominated with creativity and innovation, developing countries, like Turkey, should be very well equipped to build a competitive advantage upon technology. There is a challenge of integrating into this complex network of technology. At the enterprise level, macro policies often cannot go beyond good wishes. SMEs need correct micro-level policy making to become a part of innovation-led markets of information society.

\section{Cloud Computing and Policies to Foster SMEs' Adaptability to Clouds}

The analysis of Turkish and EU SME policies outline three important priorities in policymaking at the micro-level: (1) ensuring competitiveness, (2) adapting information society dynamics and (3) employing incentive programs to foster SME participation in knowledge economy. SME policies tend to increase the competitiveness of SMEs that bear inadequate technologies, face excessive cost of product development projects and stand unable to meet the demand for multiple technological competencies (Singh et al., 2008). Both EU and Turkey, seize that SMEs are dependent on support schemes for competitiveness and technology. European system depends upon the variety of funding mechanisms which in reality creates the most attractive part of the integration process. This is reflected also to the candidate countries and (may be not comparable with EU in numbers) in candidate countries grant schemes for SMEs are put into effect in order to harmonize wit EU. Policy-making in EU consists of three strands in three different levels; setting the policy-priorities for common market at the
EU level, identifying action plans at the member state level and providing required funding for the realization of those actions at the project level. This system is also expected to be adopted by the candidate countries. Accordingly, candidates are required to make policies in line with EU objectives, to prepare realistic action plans and lastly to offer funds that support this process. This model is valid for information society as well.

Policy-making for information society in both the European and Turkish system presents fostering competitiveness and improving ICT adaptability as the main objectives. The interesting part of cloud computing derives from the fact that it is deemed to foster competitiveness and improve ICT adaptability. Moreover, majority of the cloud supporters claim that the most important feature of clouds is cost-effectiveness. Cloud computing is positioned as a new business environment which fits into the frame that EU and Turkey want to put SMEs in.

The essential characteristics of clouds are provided and explained by NIST (2010). These include on-demand self-service, broad network access, resource pooling, rapid elasticity and measured service. For SMEs on-demand self-service is an important feature because it is the unilateral provisioning of computing capabilities. However, this demands, broadband internet access which may be a problem for SMEs in rural areas. Broad network access points availability over the network and accessibility through standard mechanisms that promote use by heterogeneous thin or thick client platforms like mobile phones. This indeed may turn into a valuable business model for mobile operators in Turkey where there is a growing mobile penetration. Resource pooling provides computing resources that are pooled to serve multiple consumers with different physical and virtual resources assigned and reassigned dynamically according to consumer demand. This is also an important issue for SMEs. It enables them to pay for their actual use and saves both money and 
time in ICT infrastructure management. Rapid elasticity capabilities appear to be unlimited and can be purchased in any quantity at any time. Measured service means that cloud systems automatically control and optimize resource use by leveraging a metering capability at some level of abstraction appropriate to the type of service (eg, storage, processing, bandwidth, and active user accounts). Measured services are another important feature for SMEs as they provide the basis for pay-for-use principle.

In practice all of these characteristics attribute individually to SMEs' competitiveness at different stages of ICT adoption. The survey entitled "An SME Perspective for Cloud Computing" and held by the European Network and Information Security Agency - ENISA (Gorniak, 2009) in 2009 identifies the main factors for SMEs to migrate to clouds. According to the findings of this research, the first three reasons behind the possible engagement in the cloud computing area are; (i) avoiding capital expenditure in hardware, software and IT support, information security by outsourcing infrastructure/platforms/services (68.1\%), (ii) flexibility and scalability of IT resources (63.8\%) and (iii) business continuity and disaster recovery capabilities $(52,8 \%)$.

According to studies of IDC, the European Union's IT sector in 2010 employs close to 8 million people of which $99 \%$ are working in SMEs (IAMCP, 2010). Jobs in the SME IT sector are expected to grow at a faster rate than total employment over the period of $2009-2014$, and this sector should stimulate over 550,000 new jobs (IAMCP, 2010). Migration to cloud computing would bring those companies new opportunities to innovate, grow and compete. Migration to clouds stays an issue of the decision-making at the enterprise level as long as it is considered as an innovation from the business perspective. Innovative ecosystems accelerate the migration for the enterprises that have already established links with those networks. Robert Whiteside, Head of
Google Enterprise, UK, Ireland and Benelux, introduces ten aspects of clouds for SMEs to consider when getting started in the cloud (Humpries, 2010). Accordingly, "moving to clouds is easy as there is no need to install new hardware or software as everything is run by the cloud provider. Different costsavings including hardware, software and maintenance may be more than anticipated. Clouds improve productivity. Cloud computing can be more secure than traditional IT. Clouds help to manage cultural adjustment and provide a more collaborative way of working by allowing people to use cloud computing applications for accessing and working in the same documents in real time. Clouds provide flexibility to scale up or scale down the business with "pay as you go" style services. Clouds meet the demands of today's teenagers, potential employees of tomorrow, who are accustomed to collaborating online and accessing their data from any mobile device at hand, not expecting to work in one location and from nine to five. Cloud computing providers experience less downtime than when managing IT in-house and any problems can be solved far quicker by being fixed centrally. Lastly, in contrast to traditional IT models which can involve expensive software licenses and long lock-in contracts, the cloud model offers far more flexibility."

So, clouds meet all of the needs, but still there is more to do. It is the policy. The US and Britain have already developed their own cloud policies that focus on the provision of cloud services for green and sustainable governance. US (Terdiman, 2009) and Britain (UK Government, 2010) introduced cloud computing initiatives that intend to cut costs on infrastructure and reduce the environmental impact of government computing systems. Yet, these polices tend to regulate the public provisions. There is certainly a need to make policies for SMEs as well. EU enters the scene at this moment and with a more sophisticated view, presents a group of priority areas that the forthcoming EU cloud policy should take into consideration for the competitiveness of 
Europe. The Cloud Report (Jeffery and Neidecker-Lutz, 2010) entitled "The Future of Cloud Computing: Opportunities for European Cloud Computing Beyond 2010" provides an analysis of Europe's position with respect to cloud provisioning and provides actions for extending and completing the capabilities of current EU cloud systems. This report identifies that clouds support SMEs and start-ups with improved elasticity, reduced time to market and easy adoption. It puts forward particular targets for the advancement of SME participation in cloud systems. Accordingly, the development and production of cloud interoperation standards and an open source reference implementation would assist European SMEs in ensuring their products and service offerings in the cloud environment which can be the widest possible market with highest customer acceptability. Even though the report emphasizes the importance of clouds in achieving the economic benefits of highly customized, enhanced offerings to SMEs with the creation of European cloud partner ecosystems, it does not provide a specific policy for SMEs engaging in cloud systems. There is still lack of policies and regulations that provide guidance for adoption and development of cloud computing (Jaeger et al., 2008)

International Association of Microsoft Channel Partners' (IAMCP, 2010) positioning paper focuses on the need of SME policies to promote economic growth through cloud computing and identifies priority actions for policymakers. Those are, creation of a digital single market for the knowledge-based economy, promotion of barrier-free international trade, developing an EU model contract for cloud services, promotion of European networks of the future, enhancement of SME competitiveness through innovation and skills promotion, ensuring trustworthiness and privacy of online transactions, fighting against cybercrime and promotion of transparency and good practices in security. IAMCP concludes the paper by highlighting that commercial efforts need to be enhanced by forwardlooking government policy efforts.

\section{SME-Oriented Policy-Making for Cloud Computing in Turkey}

Forward-looking government policy efforts are also needed in Turkey where SMEs are considered as the engines for economic growth. In Turkey, SMEs constitute $99,8 \%$ of all enterprises and provide $76,7 \%$ of employment (Cansiz, 2008). A recent report published by IGEME (Export Promotion Center of Turkey) gives a panorama of Turkey's ICT market for 2010. Accordingly, ICT market in Turkey is expected to reach US\$ 26 billion in 2010, up from the US\$ 24.6 billion for 2009 which was $4 \%$ of GDP (Turkoglu, 2010). Turkey presents a promising cloud computing market. This is also supported by leading cloud actors in Turkey (Yapici, 2010). Microsoft sees cloud computing as a new edge for SMEs which have limited ICT investment capabilities. Google Turkey claims that SMEs use cloud due to two reasons; for cost savings and security services provided by third parties. HP Turkey addresses Turkey as a country that certainly needs cloud computing and considers that there would be significant demand from SMEs. These underline the need of a cloud computing policy in Turkey and pave the way for an effective and dynamic policy-making experience.

In Turkey, policy-making initiates with the preparation of the document at the highest level which is the Development Plan. Development Plan, prepared once every five years, determines the framework for policies, priorities and targets for that planning period. It is prepared under the coordination of State Planning Organization and endorsed by the Grand Assembly of Turkey. The Specialized Committees, including ICT, is formed by representatives by public institutions, private firms, private umbrella institutions and NGO's and ensures the participatory process at the highest level in policy development (TTGV, 2010). However, there is still a need to enhance policy-making 
mechanisms in Turkey with the inclusion of higher number of related actors. It is also important to identify all the factors that contribute to the achievement of an efficient and effective policy. Knowledge creation is an important need in Turkish policy-making. It is important to achieve a more open, flexible, participative, evidence-based and timely governance that will be based on the possibility of integrating cloud computingenabled applications, services and data with the conventional policy-making in Turkey. A more participative governance model may be created by integrating mass-collaboration systems into the policy and decision- making. Those systems tend to offer user-centric and cost-effective services in cooperation with private actors, informal groups and citizens by employing new mechanisms of interest generation and articulation (Centeno et al., 2009). This kind of an approach can challenge the risk of intrusive governance and limited-scope policy-making that may hinder both the economic and technological development in information society oriented issues.

This study employs Van Schendelen's general categories of decision buttons methodology of EU lobbying process as a model for SME policy-making for cloud computing in Turkey. Van Schendelen, in his impressive book "Machiavelli in Brussels, The Art of Lobbying in the EU" presents a perfect methodology to analyze all the possible actors and factors that affect the EU lobbying process. Van Schendelen's approach helps to map the policy-making mechanisms and, moreover, outline the novel factors in policymaking that are as effective and influential as conventional ones. There are three categories of decision buttons in policymaking; the actors to approach, the factors to use and the vectors to create. Accordingly, the actors are the institutions that contribute to the policy-making, the factors are the determinants of policy-making and the vectors are the newly created factors which may influence policy-making (Van Schendelen, 2003). As far as it is known, there is no similar study in this field, taking Van Schendelen's model mapping the policymaking mechanisms as a construct for to analyze a domestic policy-making system. This is the first study that employs a totally European model to Turkey in order to identify the actors and the factors of policymaking in Turkey.

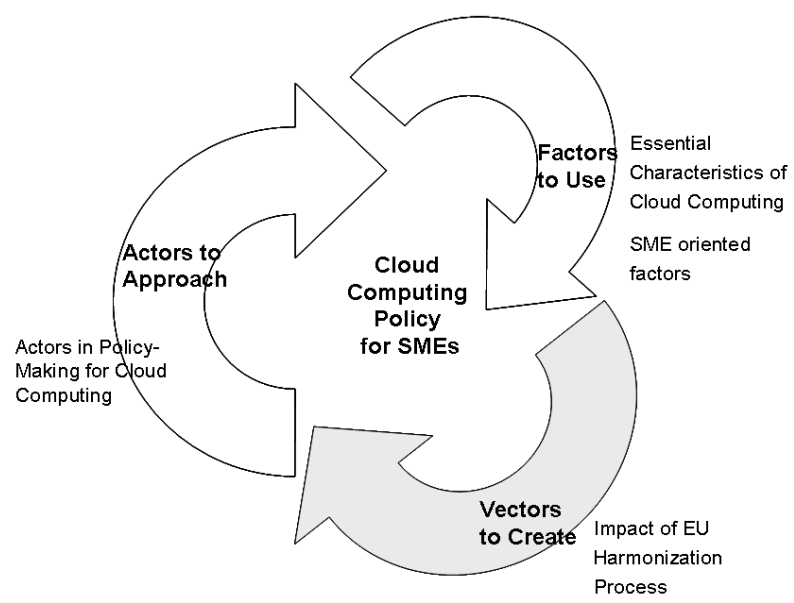

Fig 1. Illustration of Van Schendelen's General Categories of Decision Buttons Methodology as a Model for SME Policy-Making for Cloud Computing in Turkey 
Van Schendelen's general categories of decision buttons methodology of EU lobbying process is selected as a model for SME policymaking for cloud computing in Turkey due to its inclusive approach that highlights the contribution of the vectors are the newly created factors which may influence policymaking. This adoption of this methodology is novel as it is primarily developed as an instrument to analyze EU lobbying system. However, it should be noted that in candidate countries, there is need to identify EU influence as a factor in policy-making.

Actors to approach, for cloud computing policy in Turkey, involves five groups, governmental institutions, nongovernmental organizations, financial institutions, universities and local administrations. Those are the actors that are involved in policy-making. Ministry of Industry and Trade, Undersecretariat of State Planning Organization, Small and Medium Industry Development Organization (KOSGEB), The Undersecretariat of Treasury, the Undersecretariat of Foreign Trade, Ministry of Labor and Social Security, Ministry of Finance, the Scientific and Technological Research Council of Turkey (TUBITAK) are the governmental actors to approach. The Union of Chambers and Commodity Exchanges of Turkey (TOBB), the Confederation of Tradesmen and Artisans of Turkey (TESK), Vocational Training and Small Industry Supporting Foundation (MEKSA), Turkish Technology Development Foundation (TTGV), Turkish Foundation for Small and Medium Business (TOSYOV), and internet/ICT and/or sector oriented organizations like TUBISAD, TID, YASAD, TBV, TBD are the non-governmental actors to approach. ISRISK, VAKIFRISK, KOBI A.S., KGF and TESKOMB are the financial institutions. Universities provide essential support to policy-making by producing knowledge whereas local administrations like Regional Development Agencies and municipalities provide strategies and funding mechanisms for cloud computing under regional development schemes. According to the EU's informal document providing guidance to the main administrative structures in candidate countries required for implementing the acquis, for enterprise and industry policy harmonization, at least the key institutions in candidate countries such as competition authorities, development agency (FDI and export promotion), SME agency, chambers of commerce, business associations (horizontal and sectoral), Regional Development Agencies and business support centers (including Euro Info Centers) should be included in this process.

Factors to use determine the factors that affect policy-making for cloud computing. There are two set of factors; cloud computing based factors and SME oriented factors. The essential characteristics of cloud computing which are on-demand self-service, broad network access, resource pooling, rapid elasticity and measured service are the factors that improve SME competitiveness and boost economic growth. SME oriented factors are the patterns of Turkish SMEs. In this regard, competitiveness, inadequate funding for technology investments, ICT adaptation, innovativeness and awareness of new ICT services are the main factors that affect policy-making for cloud computing in Turkey.

Vectors to create cloud computing policy are the most sophisticated among all, as Van Schendelen states. Policy concepts and policy values provide cultural vectors. EU harmonization and the policies and priorities introduced by EU may form the cultural vectors to create cloud computing policy. Formal vectors are the EU acquis communitaire that are subject to legal harmonization as a part of the commitments of candidate countries. Operational vectors are the EU officials and expert groups that come and interact with Turkish counterparts. Decisional vectors are the variables of negotiation covering interest groups, crosssectoral coalitions and lobbying groups. Here, the dynamics of accession negotiations and the delegates of EU in Turkey are also influential. Turkish and European lobbying groups and the interaction between them, 
mostly the cooperation opportunities, can be referred as decisional vectors.

Turkey needs a dynamic, forward-looking, multi-dimensional, sophisticated but not chaotic, policy for cloud computing. This can only be achieved with the right selection of actors and factors that involve in policymaking. Such a policy-making process should create a consensus among decision makers who tend to govern the cloud system and the market dynamics that seek to maximize the benefits of the cloud systems. It should be built upon knowledge dissemination that leads to the enlightenment of all the possible stakeholders by employing the right information sources. The main patterns of an effective cloud policy that can be utilized as a tool of competitiveness can be outlined under five priority areas:

1.Competitiveness. Cloud computing policy should empower the SMEs for cloud computing by creating a fair, functioning market which is accessible and competitive for all possible players.

2. Access to funding. Cloud computing policy should create its own funding mechanisms in order to support SMEs and entrepreneurs that will take part in the cloud system.

3. Knowledge dissemination. Cloud computing policy should produce tools and funds for knowledge creation and dissemination.

4. Multi-level Policy Development. Cloud computing policy should be developed by the participation of all possible actors to approach. All relevant parties from different levels that would contribute to policy-making should be invited and encouraged to take part in policy-making.

5. Sustainability. Cloud computing policy should be forward-looking. It should focus on encouragement and improvement of cloud system rather than setting prohibitions to control the clouds.

\section{Conclusion}

Cloud computing phenomenon appears to be one of the most promising economic recovery tools. Cloud hype among the big companies has reflections among SMEs that see cloud computing as a cure for costreduction and technology adaptation. Even though there are numerous projects for clouds, there is still a lack of effective and efficient cloud computing policy that would stimulate SME competitiveness and facilitate migration to clouds. Turkey, like every other candidate country, adopts EU policy priorities and uses EU best practices as the basis of new policies that fall into the scope of accession negotiations. Institutional capability depends upon the ability of the candidate country to adopt differentiated national policies that complies with EU framework. In this regard, cloud computing policies of EU, forms a good sample for Turkey, as a starting point. However, Turkey needs to develop its own cloud computing policy that would foster SME competitiveness.

This paper contributes to the literature as being one of the first studies on policymaking for cloud computing in Turkey. It provides a twofold policy tool proposed for policy-makers in Turkey; mapping of policymaking and detecting the main patterns of a cloud policy focusing on SME competitiveness. First, it identifies the dynamics of policy-making in Turkey by analyzing actors to approach, factors to use and vectors to create in accordance with the model of Van Schendelen's general categories of decision buttons. It is a novel attempt that this European model is adapted to Turkish policy-making. Actors to approach, for cloud computing policy involves five groups, governmental institutions, nongovernmental organizations, financial institutions, universities and local administrations. There are two set of factors; cloud computing based factors and SME oriented factors. Vectors to create cover the factors of EU harmonization process. Secondly, it detects the main patterns of 
cloud computing policy under five priority areas: competitiveness, access to funding, knowledge dissemination, multi-level policy development and sustainability.

\section{Acknowledgement}

I would like to thank Bogazici University Research Fund for supporting the research project (5724) titled "Cloud Computing in Turkey: A Comparative Study with EU: Players, Policies, Challenges and Opportunities". I also thank Microsoft Turkey for providing academic support to this project. I also would like to express my sincere thanks to Omer Gokhan Kuyucu, Head of Consumer Services, Vodafone Turkey and Associate Professor. Ismail Ari from Ozyegin University for their gentile support to this project.

This paper is a revised version of the paper titled "Cloud Computing and SMEs: Policymaking for SME competitiveness" virtually presented in the International Business Information Management Conference (15th IBIMA) on 6-7 November 2010 in Cairo.

\section{References}

Cansiz, M. (2008). “Turkiye'De KOBI'Ler ve KOSGEB," DPT, Ankara.

Castro-Martinez, E., Jimenez-Saez, F. \& Ortega-Colomer, F. J. (2009). "Science and Technology Policies: A Tale of Political Use, Misuse and Abuse of Traditional R\&D Indicators," Scientometrics, 80(3), 829-846

Centeno, C., Lusoli, W., Misuraca, G., Punie, Y. \& Broster, D (2009). 'Key Findings, Future Prospects, and Policy Challenges, The Impact of Social Computing on the EU Information Society and Economy,' JRC Scientific and Technological Reports, Punie, Y., Lusoli, W., Centeno, C., Misuraca, G. and Broster, D. (eds), Seville, Spain.

Drori Gili, S. (2007). "Information Society as a Global Policy Agenda: What Does It Tell Us
About the Age of Globalization?," International Journal of Comparative Sociolog, 48, pp. $297-316$

Duncan-Howell, J. A. \& Lee, K.-T. (2008). "Policy Catch Up: Developing Nations and Developing ICT Policy Documents," In Proceedings British Educational Research Association (BERA) Annual Conference 2008, Herriot-Watt University, Edinburgh.

ECSS (2010). "White Paper on Software and Service Architectures, Infrastructures and Engineering - Action Paper on the Area for the Future EU Competitiveness," Volume 2: Background information, Version 1.3, [Online], [Retrieved: 15.08.2010], http://www.euecss.eu/contents/documentat ion/volume\%20two_ECSS\%20White\%20Pap er.pdf

Etro, F. (2009). "The Economic Impact of Cloud Computing on Business Creation, Employment and Output in Europe," Review of Business and Economics, 2, 179-208.

European Commission (2009). "Report of the Expert Group - Think Small First Considering SME Interests in Policy Making, Including the Application of an SME Test," [Online], [Retrieved: 15.08.2010], http://ec.europa.eu/enterprise/policies/sme /small-business-act/think-small-first/

European Commission (2010). "Communication from the Commission Europe 2020 A Strategy for Smart, Sustainable and Inclusive Growth," COM(2010) 2020, [Online], [Retrieved: 15.08.2010], http://ec.europa.eu/eu2020/pdf/COMPLET $\% 20$ EN\%20BARROSO $\% 20 \% 20 \% 20007 \% 20$ -\%20Europe $\% 202020 \% 20$ -

\%20EN\%20version.pdf

Gartner Executive Program (2010). 'The Gartner EXP CIO Report 'Leading in Times of Transition,' The 2010 CIO Agenda, 2010. [Online],[Retrieved:10.08.2010], www.gartner.com/exp. 
Gorniak, S. (2009). 'Cloud Computing European Network and Information Security Agency (ENISA),' 2009. [Online], [Retrieved: 25.06.2010],

http://www.enisa.europa.eu/act/res/techno logies/tech/dnssec/dnssec, Retrieved: 25.06.2010.

Guinet, J. (2010). "OECD Reviews of Innovation Policy: A key Customizing Tool for the OECD Innovation Strategy," Roundtable on the Innovation Strategy, Istanbul, 4thJune 2010. [Online], [Retrieved: 10.10.2010]

http://www.tubitak.gov.tr/tubitak_content_f iles//BTYPD/OECD/yenilik_stratejisi/OECD_ Roundtable_JeanGUINET.pdf

Humphries, J. (2010). "Does Cloud Computing Benefit Small Businesses?," CXO, [Online], [Retrieved: 20.10.2010],

http://www.cxo.eu.com/

IAMCP - International Association of Microsoft Channel Partners (2010). "European SMEs Seize the Cloud Policies to promote Economic Growth through Cloud Computing," Positioning Paper, 2 June 2010, Stockholm, [Online], [Retrieved: 20.10.2010], www.iamcp.org/resource/resmgr/docs/iam cp_positioning_paper_euro.pdf

Jaeger, P. T. , Lin, J. \& Grimes, J. M. (2008). "Cloud Computing and Information Policy: Computing in a Policy Cloud?," Journal of Information Technology \& Politics, 5(3), 269 $-283$.

Jeffery, K. \& Neidecker-Lutz, B. (2010). 'The Future of Cloud Computing: Opportunities for European Cloud Computing Beyond 2010,' Version 1.0, [Online], [Retrieved: 08.05.2010],

cordis.europa.eu/fp7/ict/ssai/docs/cloudreport-final.pdf

Koschatzky, K. (2009). "The Uncertainty in Regional Innovation Policy: Some RationAles and Tools for Learning in Policy Making," Working Papers Firms and Region,
No. R6/2009, Fraunhofer Institute for Systems and Innovation Research, Karlsruhe.

Misra, S. C. \& Mondal, A. (2010). "Identification of a Company's Suitability for the Adoption of Cloud Computing and Modeling its Corresponding Return on Investment," Mathematical and Computer Modeling, doi:10.1016/j.mcm.2010.03.037

Molas-Gallart, J. \& Davies, A. (2006). "Toward Theory-Led Evaluation: The Experience of the European Science, Technology and Innovation Policies," American Journal of Evaluation, 27 (1), (2006), pp. 64-82.

NIST (2010). 'NIST Definition of Cloud Computing,' [Online], [Retrieved: 08.05.2010], csrc.nist.gov/groups/SNS/cloudcomputing/cloud-def-v15.doc

Piccaluga, A. (200). 'Conclusions Variety and Miracles for Successful Regional Innovation Policies: from Copy and Paste to Copy and Paste Special,' Regional Development in the Knowledge Economy, Cooke F. and Piccaluga A. eds, Routledge, NY, 272-277.

Sharma, M., Mehra, A., Jola, H., Kumar, A., Misra, M. \& Tiwar, V. (2010). 'Scope of Cloud Computing in India,' Journal of Computing, 2:5, 144-149.

Singh, R. K., Garg, S. \& Deshmukh, S. G. (2008). "Strategy Development By SMEs for Competitiveness: A Review," Benchmarking An International Journal, 15(5), 525-547.

State Planning Organization (2004). 'SME Strategy and Action Plan,' [Online], [Retrieved: 08.05.2010], www.dpt.gov.tr/DocObjects/3078/strateji.p df

State Planning Organization (2006). 'SME Strategy and Action Plan,' (2007-2009), [Online], [Retrieved: 08.05.2010], http://ekutup.dpt.gov.tr/esnaf/kobi/strateji /2007.pdf. 
Stinchcombe, N. (2009). "Cloud Computing in the Spotlight," Infosecurity.com, 26 October 2009. [Online], [Retrieved: 10.09.2010], http://www.infosecurity-

magazine.com/view/4755/cloud-computingin-the-spotlight/

Subashini, S. \& Kavitha, V. (2010). "A Survey on Security Issues in Service Delivery Models of Cloud Computing," Journal of Network and Computer Applications, doi:10.1016/j.jnca.2010.07.006

Sultan, N. A. (2010). "Reaching for the "Cloud": How SMEs Can Manage," Computer and Information Science,

DOI: $10.1016 /$ j.ijinfomgt.2010.08.001

UK Government (2010). 'Cloud Computing in the UK Government,' [Online], [Retrieved: 08.09.2010], www.cloudbook.net/ukcloudgov

Van Schendelen, R. (2003). Machiavelli in Brussels, the Art of Lobbying in the EU, Amsterdam University Press, Amsterdam.

Vaquero, L. M., Rodero-Merino, L., Caceres, J. \& Lindner, M. (2009) "A Break in the Clouds: Towards a Cloud Definition," ACM SIGCOMM Computer Communication Review, 39(1), 5055.

Terdiman, D. (2009). "White House unveils Cloud Computing Initiative," Cnet News, September 15, 2009, [Online], [Retrieved: 20.09.2010],

http://news.cnet.com/8301-13772_310353479-52.html\#ixzz1083ziGXD.

TTGV (2010). "Science, Technology and Innovation Policy Documents," 2010. [Online], [Retrieved: 20.09.2010], http://www.ttgv.org.tr/en/policydocuments

Turkoglu, Y. (2010). "ICT Sector in Turkey," IGEME, [Online], [Retrieved: 20.09.2010], www.igeme.org.tr/Assets/sip/san/ICT.pdf
Yapıcı, C. (2010). "Bulut Bilisim Dosyasi," [Online], [Retrieved: 20.09.2010], www.tubisad.org.tr/Tr/Library/Analizler/bu lut_bilisim_dosyasi.pdf 